\title{
Prediction of Spontaneous Regression of Cervical Intraepithelial Neoplasia Lesions Grades 2 and 3 by Proteomic Analysis
}

\author{
Kai-Erik Uleberg, ${ }^{1,2}$ Irene Tveiterås Øvestad, ${ }^{3}$ Ane Cecilie Munk, ${ }^{4}$ \\ Cato Brede, ${ }^{5}$ Bianca van Diermen, ${ }^{3}$ Einar Gudlaugsson, ${ }^{3}$ \\ Emiel A. M. Janssen, ${ }^{3}$ Anne Hjelle, ${ }^{2,6}$ and Jan P. A. Baak ${ }^{3,7}$ \\ ${ }^{1}$ Norconsult AS, Section 355 QA Service, P.O. Box 216, NO-4503 Mandal, Norway \\ ${ }^{2}$ Former International Research Institute of Stavanger (IRIS), P.O. Box 8046, 4068 Stavanger, Norway \\ ${ }^{3}$ Pathology Department, Stavanger University Hospital, P.O. Box 8100, 4068 Stavanger, Norway \\ ${ }^{4}$ Department of Gynecology and Obstetrics, Stavanger University Hospital, P.O. Box 8100, 4068 Stavanger, Norway \\ ${ }^{5}$ Department of Medical Biochemistry, Stavanger University Hospital, P.O. Box 8100, 4068 Stavanger, Norway \\ ${ }^{6}$ Mediteam AS, Sjøveien 34, 4315 Sandnes, Norway \\ ${ }^{7}$ The Gade Institute, University of Bergen, P.O. Box 1400, 5021 Bergen, Norway
}

Correspondence should be addressed to Irene Tveiterås Øvestad; ovir@sus.no

Received 30 January 2014; Revised 29 April 2014; Accepted 14 May 2014; Published 15 June 2014

Academic Editor: Jen-Fu Chiu

Copyright (C) 2014 Kai-Erik Uleberg et al. This is an open access article distributed under the Creative Commons Attribution License, which permits unrestricted use, distribution, and reproduction in any medium, provided the original work is properly cited.

\begin{abstract}
Regression of cervical intraepithelial neoplasia (CIN) 2-3 to CIN 1 or less is associated with immune response as demonstrated by immunohistochemistry in formaldehyde-fixed paraffin-embedded (FFPE) biopsies. Proteomic analysis of water-soluble proteins in supernatants of biopsy samples with LC-MS (LTQ-Orbitrap) was used to identify proteins predictive of CIN2-3 lesions regression. CIN2-3 in the biopsies and persistence (CIN2-3) or regression ( $\leq \mathrm{CIN1})$ in follow-up cone biopsies was validated histologically by two experienced pathologists. In a learning set of 20 CIN2-3 (10 regressions and 10 persistence cases), supernatants were depleted of seven high abundance proteins prior to unidimensional LC-MS/MS protein analysis. Mean protein concentration was $0.81 \mathrm{mg} / \mathrm{mL}$ (range: $0.55-1.14$ ). Multivariate statistical methods were used to identify proteins that were able to discriminate between regressive and persistent CIN2-3. The findings were validated in an independent test set of 20 CIN2-3 (10 regressions and 10 persistence cases). Multistep identification criteria identified 165 proteins. In the learning set, zinc finger protein 441 and phospholipase D6 independently discriminated between regressive and persistent CIN2-3 lesions and correctly classified all 20 patients. Nine regression and all persistence cases were correctly classified in the validation set. Zinc finger protein 441 and phospholipase D6 in supernatant samples detected by LTQ-Orbitrap can predict regression of CIN2-3.
\end{abstract}

\section{Introduction}

Among cancers affecting women, cervical cancer has the second highest occurrence worldwide, with an incidence in 2008 of 529,800 cases $(14.5 \%$ in developed countries and $85.5 \%$ in developing countries) and 275,000 estimated deaths [1]. Infection of cervical epithelial cells with high risk human papillomavirus (HPV) is the most important risk factor for development of cervical cancer, as first highlighted by zur Hausen [2]. Noninvasive cervical intraepithelial neoplasia (CIN) precedes the development of invasive cancer and may progress from CIN2-3 to (micro)invasive cancer in 10-25 years on average [3].

Three CIN grades (CIN1, CIN2, and CIN3) are recognized by the World Health Organization to distinguish the degrees of epithelial abnormality and are associated with increasing 
risks for invasive cancer development. A CIN lesion is, however, not a static event but a dynamic process that can persist and progress but also spontaneously regress $[4,5]$. If left untreated, 5-30\% of all CIN2-3 lesions (confirmed by a histological punch biopsy) will develop invasive cancer [6]. On the other hand, without cone excision, as many as $32-43 \%$ of CIN2-3 lesions will regress spontaneously [7]. Nevertheless, in many countries including Norway, all punch biopsy-confirmed CIN2-3 lesions are usually treated with diathermic cone excision, a fairly aggressive therapy which can have serious adverse side effects [8]. The most serious late-complication is cervical insufficiency which can lead to late abortion and preterm delivery during the second and early third trimester of a future pregnancy $[9,10]$.

Until recently, regression of CIN2-3 lesions could not be effectively predicted. However, research on functional biomarkers like pRb, p53, and cytokeratin 13/14 has proven to be helpful in predicting regression, especially when combined with local immune response and HPV genotype [11-14]. Furthermore, combined Ki67 and pRb expression can predict which CIN1 lesions will progress to CIN3 [15]. Aggregated information provided by such epithelial biomarkers and local cellular immune response in the microenvironment of CIN2-3 lesions supports prediction of regression/persistence/progression and may result in even more accurate CIN treatment, [16] as well as reducing overtreatment of patients with CIN2-3 lesions.

Unfortunately, the procedures used to obtain formalinfixed, paraffin-embedded (FFPE) tissue from biopsies irreversibly degrade water-soluble proteins. A protein collection method for small punch biopsy samples that could represent not only the cellular response but also proteins from the cervical neoplasia microenvironment and intracellular compartments may further help define the biology of CIN lesions' dynamic behaviour. We have recently described a method that can preserve and extract water-soluble proteins from punch biopsies [17], how a panel of 3 peaks from SELDITOF protein profiles can be used to differentiate normal tissue from CIN tissue samples, and that a discrimination between CIN2 and CIN3 lesions could be obtained using cytokeratin $2[18]$.

In the present study we analysed protein samples from CIN2-3 lesions with known regression/persistence status. We have used both SELDI-TOF MS and bottom-up shotgun proteomics [19] approach utilizing nanoflow liquid chromatography coupled to a LTQ-Orbitrap mass spectrometer. The goal was to identify proteins that could be used in prediction of regression or persistence in CIN2-3.

\section{Materials and Methods}

2.1. Study Population. This study is a subproject from a larger prospective study, approved by the Regional Medical Ethics Committee of Helse Vest, Norway, the Norwegian Data Inspection, and the Health Directorate of Norway, numbers $33.06,17185$, and $07 / 330$. Healthy women aged $25-40$ years, with cytological abnormal smears were followed by cervical biopsy and later cone excision. In total, 170 patients with first time onset of CIN2-3 were included from January 2007 to December 2008. The interval between punch biopsy and cone excision was standardized at median 113 days (range: 100-126). This interval was chosen in view of a previous study, which showed that CIN2-3 patients with more than 9 -week punch-cone interval have a much higher chance on regression than those with $<9$-week interval [5]. Regression was defined as CIN1 or less in cone histology and regression rate was $22 \%(38 / 170)$. All patients included in this study were treated according to the national Norwegian population screening quality guidelines [20].

In our cohort of patients we first analysed whether proteins and peptides detected by proteomic LC-MS (LTQOrbitrap) could distinguish between CIN2-3 lesions, with and without later regression. Of the 170 patients with cervical punch biopsy samples, a random subset of 20 patients with cervical intraepithelial neoplasia lesions (see below for reviewing details), 10 CIN2 (5 with regression and 5 with persistence) and $10 \mathrm{CIN} 3$ (5 with regression and 5 with persistence), were selected and defined as the learning set. The histological diagnosis was set by two experienced pathologists. The samples were selected so that the whole sampling period was covered and the protein concentration was as close as possible to the average for the whole data set. In a second validation study, another 20 CIN2-3 patients (10 CIN2 cases, 5 with regression and 5 with persistence, and 10 CIN3, 5 with regression and 5 with persistence, defined as the validation set) were selected to test the prognostic value of the proteins found in the learning set.

For the SELDI-TOF study, the sample set from a former investigation was used [21]. These samples were statistically reanalysed with regard to the regression/persistence status. Thus 2 replicates of each of the 5 regression and 40 persistent CIN2-3 samples were included for this part of the study.

2.2. Sample Collection. After colposcopy, punch biopsies and endocervical curettage were taken from the transformation zone and eventually premalignant mucosa. One or two biopsies were immediately placed in polystyrene tubes (Sarsted, Numbrecht, Germany) containing 5 mL RPMI-1640 (Gibco, Carlsbad, USA) tissue culture medium. The biopsies were kept in the tissue culture medium for 24 hours at $4^{\circ} \mathrm{C}$ before the supernatants were collected, split into aliquots of $500 \mu \mathrm{L}$, and stored at $-80^{\circ} \mathrm{C}$ until analysis. Immediately after sample collection, an additional set of biopsies were stored in $4 \%$ buffered formaldehyde according to standard procedure.

2.3. Pathology. As described before [17] after 24 hours of incubation in RPMI-1640 medium at $4^{\circ} \mathrm{C}$, the biopsies were routinely fixed in buffered $4 \%$ formaldehyde, embedded in paraffin, cut at $4 \mu \mathrm{m}$, and stained with hematoxylin, eosin, and safran (HES) for routine histological examination. P16 and Ki67 (MIB-1) immunohistochemical (IHC) staining were used to confirm the diagnosis. All HES and IHC sections of the 170 biopsies were reviewed by two independent pathologists, who also used the p16 and Ki67 immunohistochemical information. The participating pathologists were blinded to the original routine clinical findings, histopathological 
diagnosis, and follow-up. In case of discrepancies the cases were reviewed and diagnosed on a double-head microscope by the two pathologists (Einar Gudlaugsson and Jan Baak) and a consensus diagnosis was obtained.

2.4. ProteinChip SELDI-TOF MS Analysis. Protein concentrations were assessed using the Bradford methodology. Samples were subjected to SELDI-TOF MS profiling according to the manufacturer's instructions (Ciphergen Biosystems, Fremont, CA, USA). The biopsy supernatants were diluted 1:5 with $50 \mathrm{mM}$ sodium acetate $(\mathrm{pH} 4.3)$ and then bound to a CM10 ProteinChip array. They were incubated for two hours at room temperature on a platform shaker and then washed twice with $50 \mathrm{mM}$ sodium acetate buffer, followed by two washes of $1 \mu \mathrm{L}$ energy absorbing molecule (=EAM) solution (consisting of $50 \%$ saturated synaptic acid dissolved in $50 \%$ acetonitrile and $0.5 \%$ trifluoroacetic acid). Two replicates were prepared on different CM10 ProteinChips by two different technicians on two different days. The timeof-flight spectra were generated on the Protein Biological System II mass spectrometer reader (Ciphergen Biosystems, Fremont, CA, USA), using a laser intensity of 170 and a detector sensitivity of seven. Readings were optimized for low molecular weight (2-20 kDa). External mass calibration was performed daily.

2.5. SELDI-TOF MS Data Analysis. The SELDI-TOF MS data analyses were performed in three steps: (1) peak detection, (2) selection of peaks with the highest discriminatory power, and (3) building a multivariate model based on the selection in step (2). The peak detection was done using the Ciphergen Seldi software version 3.2 after internal and external mass calibration followed by normalization (total ion current, TIC, intensity) of all spectra as one group. The mass range from 2000 to $20000 \mathrm{Da}$ contained the majority of the peptides/proteins in the samples and was selected. Masses less than $2000 \mathrm{Da}$ were excluded as these are known to contain adducts and artifacts from the EAM solution and other chemical contaminants. The peak detection includes baseline subtraction, calibration of mass accuracy, and automatic peak detection. Each spectrum was then assigned to one of three groups, normal, regression, or persistence. To select peaks with the highest discriminatory power, the Biomarker Wizard (Ciphergen) was used for peak detection and clustering of all the spectra. This was done using a signal-to-noise $(\mathrm{s} / \mathrm{n})$ ratio of 5 and $15 \%$ of all spectra for the first pass detection and clustering and an $\mathrm{s} / \mathrm{n}$ ratio of 2 for the second pass. The cluster results were then imported into SPSS (v17, SPSS Norway AS, Oslo, Norway), CART (Salford, San Diego, CA, USA), and MedCalc (MedCalc Software, Mariakerke, Belgium) for binary logistic regression analysis.

2.6. Immunoaffinity Depletion. The preparation and use of the immunoaffinity column is described in [17]. To deplete samples of the 7 high abundance proteins, $100 \mu \mathrm{L}$ of RPMI supernatant was diluted with $100 \mu \mathrm{L}$ Tris-buffered saline (TBS, $0.1 \mathrm{M}$ TRIS-base containing $0.1 \mathrm{M} \mathrm{NaCl}, \mathrm{pH} 8.0$ ), and the solution was injected into a TBS solution with a flow of $0.2 \mathrm{~mL} / \mathrm{min}$. The nonretained proteins were trapped on a $4 \mathrm{~mm} \times 2.0 \mathrm{~mm}$ (inner diameter, i.d.), $\mathrm{C}_{18}$ security guard cartridge with $300 \AA$ A pore size (Phenomenex, Teknolab, Norway) and were eluted by backflushing the security guard cartridge with ethanol at a flow of $0.3 \mathrm{~mL} / \mathrm{min}$. The affinity column was washed using $0.1 \mathrm{M}$ glycine at $\mathrm{pH} 2.5$ with a flow of $1.2 \mathrm{~mL} / \mathrm{min}$. Both columns were reequilibrated with TBS at a flow of $0.2 \mathrm{~mL} / \mathrm{min}$ for 5 minutes. The $\mathrm{pH}$ adjustments were done using $6 \mathrm{M} \mathrm{HCl}$.

2.7. Protein Digestion and Sample Cleanup. After evaporating the ethanol phase containing the nonretained protein fraction using vacuum centrifugation (Eppendorf Concentrator 5301, VWR, Norway), $100 \mu \mathrm{L} 50 \mathrm{mM}$ ammonium bicarbonate $\mathrm{pH} 8$ was added to the samples. $1 \mu \mathrm{L}$ of $1 \mathrm{M}$ dithiothreitol (DTT) was added to reduce the proteins. $5 \mu \mathrm{L}$ of $1 \mathrm{M}$ iodoacetamide (IAA) was then added to alkylate the proteins followed by $5 \mu \mathrm{L}$ of DTT to stop the alkylation process. For each of these steps, 45-minute incubation time was used. One $\mu \mathrm{g}$ trypsin (Promega) was added, and the samples were kept at $37^{\circ} \mathrm{C}$ for 18 hours. After digestion with trypsin the samples were purified and concentrated using a $\mathrm{C}_{18}$ ZipTip (Millipore, Norway) procedure. The ZipTips were conditioned by aspirating $30 \mu \mathrm{L}$ acetonitrile five times and equilibrated with pulling $30 \mu \mathrm{L} 0.1 \%$ formic acid (FA) in MilliQ water five times through the stationary phase. Approximately $10 \mu \mathrm{L}$ of the $0.1 \%$ FA solution was left above the stationary phase to avoid drying it. Each sample solution was applied on top of the stationary phase using a pipette and then pushed through the tip using air pressure from the pipette plunger. More sample solution was added when approximately $20 \mu \mathrm{L}$ of the liquid remained so that the whole volumes of the samples were pushed slowly through the ZipTip. Washing was done by aspiring $30 \mu \mathrm{L}$ of $0.1 \%$ FA five times. Elution of the peptides was done in a total volume of $30 \mu \mathrm{L}$ of $80: 20(\mathrm{v} / \mathrm{v})$ acetonitrile : MilliQ water by aspiring $10 \mu \mathrm{L}$ of this solution 10 times through the stationary phase. The organic phase was then evaporated using vacuum centrifugation and, to the residual solution, $20 \mu \mathrm{L} 0.1 \%$ FA was added prior to the LCMS/MS analysis.

2.8. LC-MS/MS Analysis. A Dionex Ultimate 3000 nanoflow HPLC equipped with a $300 \mu \mathrm{m}$ (i.d.) $\times 0.5 \mathrm{~cm}$ length Acclaim PepMap $100 \mathrm{C}_{18}$ trap column and a $75 \mu \mathrm{m}$ (i.d.) $\times$ $15 \mathrm{~cm}$ Acclaim PepMap $100 \mathrm{C}_{18}$ analytical column (Dionex) was used with a LTQ-Orbitrap hybrid mass spectrometer (Thermo Scientific). $5 \mu \mathrm{L}$ of the tryptic digests was injected onto the trap column using $0.1 \%$ formic acid (VWR) in MilliQ-water at a flow of $2 \mu \mathrm{L} / \mathrm{min}$. The separation was done using a gradient from $2.5 \%$ to $64 \%$ acetonitrile in $0.1 \% \mathrm{FA}$ over 180 minutes at a flow of $300 \mathrm{~nL} / \mathrm{min}$. A 10-minute postinjection delay and a 20 -minute column reequilibration time were used. The electrospray interface was a PicoTip emitter (SilicaTip, New Objective) with a $10 \mu \mathrm{m}$ tip without coating. The electrospray voltage was set to $1 \mathrm{kV}$. No sheath gas was used. The mass spectrometer was used in positive mode. Full scans were performed in the Orbitrap using the $\mathrm{m} / z$ range from 200 to 2000 . Data dependent MS/MS scans 
were performed in the LTQ for the five most abundant masses with $z \geq 2$ and intensity higher than 10,000 counts. Dynamic exclusion for 3 minutes after fragmentation of a given $\mathrm{m} / z$ value four times was used. Collision induced dissociation (CID) was used with a collision energy of $35 \%$, activation Q setting of 0.400 , and $30 \mathrm{~ms}$ activation time for MS. Calibration of the mass spectrometer was done weekly using the calibration solution recommended by Thermo Scientific.

2.9. Bioinformatic Data Analysis. The raw data files were analysed using the Proteome Discoverer 1.0 (Thermo Scientific) with the Sequest algorithm to search against the Homo sapiens (Tax.id: 9606) database at NCBI (531420 sequences) with trypsin as digestion enzyme allowing for 2 missed cleavages. All files were also searched against the human papillomavirus database (Tax.id: 10566) at NCBI (1615 sequences). Precursor ion tolerance was set to $10 \mathrm{ppm}$, and fragment ion mass tolerance was set to $0.8 \mathrm{Da}$. Oxidation (M) was set as a dynamic modification and carbamidomethyl (C) was set as a static modification due to the use of DTT and IAA. Phosphorylation (STY) was set as a dynamic modification. A high significance peptide confidence filter was set in Proteome Discoverer (PD) from Thermo, which means that peptide identifications are filtered based on the following combination of charge and Xcorr factor: $1.9(z=$ 2), $2.3(z=3)$, and $2.6(z \geq 4)$. Additional information for proteins was obtained from the UniProt database entry.

Protein identifications were accepted using one peptide when certain requirements were fulfilled: the Sequest Xcorr factor with regard to charge had to be fulfilled according to the high significance criteria in PD. The peptide had to contain at least 7 amino acids and have at least three consecutive b- and y-ions in the MS2 spectra [22], and it should occur minimum three times in the same sample. In addition, for proteins with only one identified peptide sequence, the peptide sequences were submitted for a BLAST search against the Uniprot Homo sapiens database (http://www.uniprot.org/) to confirm that the identification matched the NCBI identification. For proteins listed as unnamed in the NCBI database, the ID mapping tool at UniProt was used to see if the protein was listed with a more descriptive annotation in this database. Only proteins identified in at least $30 \%$ of the samples in one of the groups (regression/persistence) were included in the remaining work. Spectral count (SPC) results for the identified peptides were obtained and used for normalization (see (1)) after increasing all numbers with 1 to avoid zeros. Consider

$$
\begin{aligned}
& \text { SPC Norm } \operatorname{Nrotein} x \text {, Sample } x \text {, Group } y \\
& =\mathrm{SPC}_{\text {Protein } x \text {, Sample } x} \times \frac{\text { Sum } \mathrm{SPC}_{\text {Sample } x}}{\text { Avg. SPC }} .
\end{aligned}
$$

2.10. Multivariate Analysis of the LC-MS/MS Data. The normalized SPC results were imported into Sirius (version 8.1, Pattern Recognition Systems, Bergen, Norway) to perform a partial least-squares discriminant analysis (PLS-DA) using a target projection component, calculations of selectivity ratios
(SR), plotting of SR-values, and a discriminating variable (DIVA) test. A binary response variable was added to the SPC dataset to assign all samples to one of the two groups (i.e., regression $=0$ and persistence $=1$ ), making it a supervised method. Partial least-squares discriminant analysis (PLS$\mathrm{DA}$ ) is a suitable method when the within group variance is comparable or dominant compared to the between group variance [23]. The maximum group discrimination from a PLS-DA model can be represented by a target projection (TP) component that is obtained by combining all PLS components into this single TP component using a latent variable projected onto the response variable [24]. A score value from the target projection model is calculated for each object (sample) with regard to the group variable. A selectivity ratio (SR) plot resembles a spectrum and is a plot of the ratio of explained variance to unexplained variance for each variable [25], where one variable in this case is an identified protein. Variables with high selectivity ratios have high discriminating ability between the two groups. The discriminating variable (DIVA) test is a nonparametric test suitable for small sample sets with group heterogeneity [24]. A correct classification rate (CCR) value is calculated for each variable and will vary between $50 \%$ for a variable that provides random classification of the samples and $100 \%$ for a variable that gives a complete separation of the two groups. The SR and CCR are closely related in that higher SR should give higher CCR. The DIVA test provides a means of setting boundaries for the selectivity ratio to identify the important discriminating variables (proteins in this case) for a given CCR. More in depth theoretical explanations of all these methods can be found in [23-25]. The model was crossvalidated by leaving out a large percentage of the individual samples from both sets in two cross-validation steps. In an outer loop, $20 \%$ of the samples were kept out at a time for an external validation. This was repeated 5 times so that all samples were kept out once. In the inner loop, $25 \%$ of the samples were kept out at a time, and this was repeated four times to keep out all samples once.

The normalized spectral count data were also imported into SPSS (version 18, SPSS, Oslo, Norway) for a binary logistic regression analysis and CART (Salford, San Diego, CA, USA) for a classification and regression tree analysis, both used as supervised in the sense that a group variable (regression or persistence) was added. The continuous variables were divided into two different subgroups, using a threshold value assessed by receiver-operating curve (ROC) analysis (MedCalc Software, Mariakerke, Belgium).

\section{Results}

The median age of the patients at inclusion was 29.7 years (range: 25-40), the interval between punch biopsy and cone excision was median, 113 days, and the mean protein concentration of the selected RPMI samples, measured by Bradford, was $0.81 \mathrm{mg} / \mathrm{mL}$ (range: $0.55-1.14$ ). The age, punchcone excision interval, and protein concentration of the 
RPMI samples of each of the three groups of patients studied (i.e., LC-MC/MS learning set, validation set, and the SELDITOF set) were consistent with the overall cohort from which our samples were selected and therefore can be regarded as representative.

3.1. SELDI-TOF MS Results. A total of 40 peaks were detected in the SELDI-TOF spectra using the criteria described in Section 2.5. The development of a binary logistic regression model resulted in one protein peak $(m / z$ 6034) having the best discriminatory power between the regression and persistence samples of the 40 peaks in this dataset. Figure 1 is a scatter plot showing this peak plotted against one of the peaks found as discriminatory between normal and CIN23 tissue in the previous study [21]. The figure shows that this SELDI-TOF peak in fact could not discriminate between CIN2-3 lesions with regression and persistence.

3.2. LC-MS/MS Results. The samples were subjected to depletion of 7 high abundance proteins followed by tryptic digestion and unidimensional LC-MS/MS analysis. Using the high significance peptide confidence filter in Proteome Discoverer and the identification criteria for proteins with only one peptide, a total of 165 protein identifications were included (all listed in Table 1 and more detailed in Supplementary Tables 1 and 2, see Supplementary Material available online at http://dx.doi.org/10.1155/2014/129064): 57 of these were identified with two or more unique peptides and the others with only one unique peptide. Although peptides from human papillomavirus proteins were detected in all samples, none of them gave acceptable protein identification.

Figure 2 shows a plot of the target projection score results from the complete dataset. The discrimination between the regression and persistence group is $95 \%$ since all persistence samples have score values with a positive sign, and 19 out of the 20 regression samples have a negative score value.

Figure 3 shows a selectivity ratio plot for all the identified proteins resulting from doing a DIVA test with $90 \%$ correct classification rate set as an objective goal. This resulted in a selectivity ratio of \pm 1.26 as the limit for a variable to be significant in discriminating the groups. These limits are shown as solid horizontal lines in the figure.

Only one protein, the zinc finger protein 441 (ZNF441) (gi308153532) (red box), had a selectivity ratio of 1.26.

The CART analysis of the learning set resulted in a two-node model in which the ZNF441 was used as the primary group discriminator and, "similar to CG12314 gene product", as the second most contributing discriminator. This protein was identified with one peptide (RVLITGSLNWTTQAIQNNR, precursor $m / z$ : $2265.1714 \mathrm{Da}$, charge: +2 ). A Blast search against the UniProt human database with this sequence gave only one hit, phospholipase D6 (PLD6) (UniProt identifier: Q8N2A8). A search using the IDmapping tool at the UniProt website gave no results. However, a UniProt Blast search for the complete sequence from the NCBI entry resulted in a unique hit with $100 \%$ identity score, PLD6.

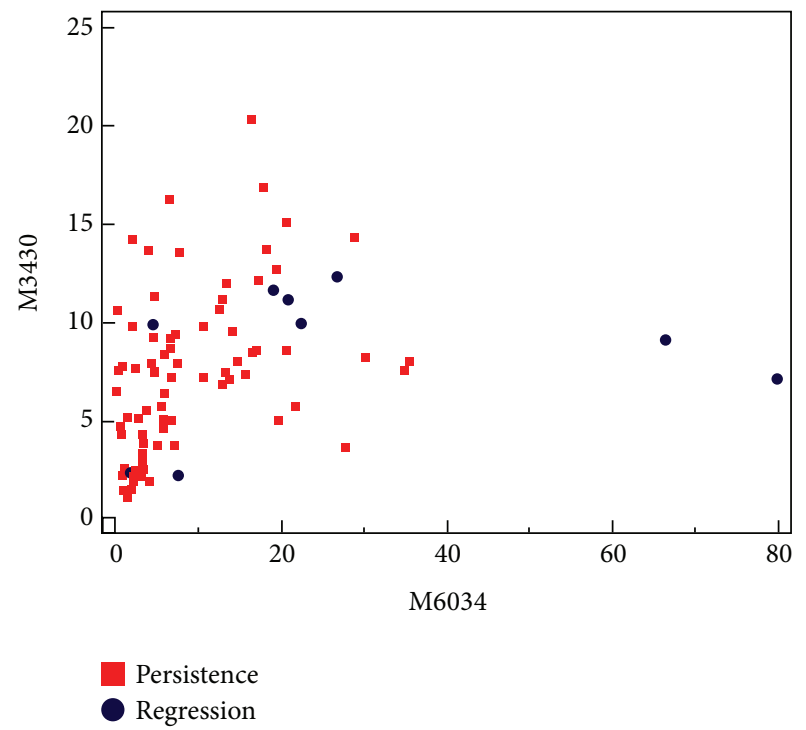

FIGURE 1: Scatter plot of the SELDI-TOF MS results for the peaks with $m / z 6034$ and $m / z 3430$ (samples: $n=5$ regression and $n=$ 40 persistence, 2 replicates of each). The figure illustrates that no discrimination is obtained between the regression and persistence groups using these results.

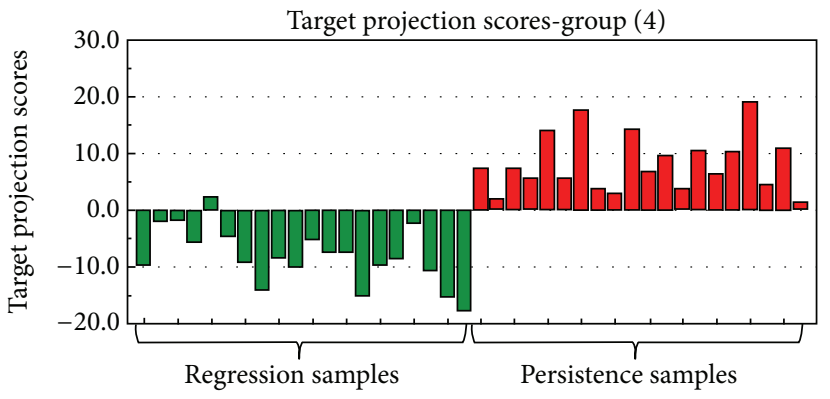

FIGURE 2: Score plot of discrimination between the regression group and persistence group after the target projection analysis.

Figure 4 shows a scatter plot using the spectral count results for these two proteins of the two sets and illustrates the discrimination obtained.

The binary logistic regression model also resulted in ZNF441 having highest discriminatory power (results not shown).

ZNF441, identified using one highly significant peptide (QCGKALSHLKSFQR), was found in 10 and 9 of the 10 regression samples in the learning and validation set, respectively, and in none of the persistence samples. The PLD6 protein was also identified using only one high significance peptide and occurred in 7 and 5 of the 10 regression samples in the two sets.

Figure 5 shows the peptide sequence, the MS2 spectrum, and the $y$ - and b-series for the ZNF441 peptide.

A Blast search using the peptide sequence against the human UniProt database gave the two ZNF441 isomers as 
TABLE 1: List of 165 proteins identified with high significance filter in Proteome Discoverer.

\begin{tabular}{|c|c|c|c|c|}
\hline $\begin{array}{l}\text { Accession } \\
\text { number }\end{array}$ & $\begin{array}{l}\text { Number } \\
\text { of AAs }\end{array}$ & MW [Da] & Description & $\Sigma$ Coverage \\
\hline 25777600 & 953 & 105769 & $26 \mathrm{~S}$ proteasome non-ATPase regulatory subunit 1 & 1,1 \\
\hline 92090990 & 757 & 86306 & Activating signal cointegrator 1 complex subunit 2 & 1,7 \\
\hline 119631843 & 438 & 48626 & Activin A receptor, type I & 7,3 \\
\hline 90819233 & 1651 & 187556 & Afadin isoform 2 & 1,5 \\
\hline 112877 & 201 & 23497 & Alpha-1-acid glycoprotein 1 & 15,9 \\
\hline 119598593 & 366 & 39172 & Alpha-2-HS-glycoprotein & 5,7 \\
\hline 224809474 & 951 & 106839 & Ankycorbin isoform B & 3,5 \\
\hline 119573007 & 92 & 10573 & Apolipoprotein A-II & 52,2 \\
\hline 119621207 & 3000 & 338317 & Apolipoprotein B (including $\mathrm{Ag}(\mathrm{x})$ antigen) & 0,8 \\
\hline 73622085 & 665 & 72088 & ATPase WRNIP1; AltName: Werner helicase-interacting protein 1 & 2,4 \\
\hline 85700402 & 1704 & 191239 & ATP-binding cassette subfamily A member 3 & 2,1 \\
\hline 14916956 & 633 & 69181 & $\begin{array}{l}\text { ATP-dependent Clp protease ATP-binding subunit clpX-like, } \\
\text { mitochondrial }\end{array}$ & 3,2 \\
\hline 260763963 & 652 & 73680 & B-cell scaffold protein with ankyrin repeats isoform 3 & 2,8 \\
\hline 410564 & 27 & 2891 & Beta-trace $\{\mathrm{N}$-terminal $\}$ & 74,1 \\
\hline 119630319 & 616 & 69142 & BTB and CNC homology 1, basic leucine zipper transcription factor 1 & 3,4 \\
\hline 110618250 & 651 & 69567 & Cadherin-related family member 5 isoform 3 & 2 \\
\hline 93204551 & 754 & 85485 & Calpain-7-like protein & 2,3 \\
\hline 119621019 & 2225 & 242829 & $\begin{array}{l}\text { Carbamoyl phosphate synthetase } 2 \text {, aspartate transcarbamylase, and } \\
\text { dihydroorotase }\end{array}$ & 0,6 \\
\hline 215274265 & 626 & 70812 & Carnitine O-acetyltransferase & 2,1 \\
\hline 119588550 & 361 & 39391 & CD44 antigen (Indian blood group) & 3,3 \\
\hline 151101301 & 550 & 60746 & Centrosomal protein POC5 isoform 2 & 6,7 \\
\hline 171184451 & 3117 & 350716 & Centrosome-associated protein 350 & 0,9 \\
\hline 283135365 & 21 & 2382 & Chain A, human insulin & 100 \\
\hline 289526593 & 120 & 13375 & Chain B, crystal structure of monomeric human cystatin C & 9,2 \\
\hline 296278495 & 120 & 13562 & $\begin{array}{l}\text { Chain B, crystal structure of the second bromodomain of human } \\
\text { polybromo (protein polybromo-1) }\end{array}$ & 14,2 \\
\hline 295789308 & 153 & 15779 & Chain B, human sod1 D124v variant & 64,7 \\
\hline 293651901 & 243 & 28061 & $\begin{array}{l}\text { Chain B, solution structure of double super helix model } \\
\text { (apolipoprotein A-I) }\end{array}$ & 33,3 \\
\hline 289526844 & 220 & 24615 & $\begin{array}{l}\text { Chain B, structural basis of membrane-targeting by dock } 180 \\
\text { (dedicator of cytokinesis protein } 1 \text { ) }\end{array}$ & 8,6 \\
\hline 291463533 & 127 & 13753 & Chain B, wild type human transthyretin (Ttr) & 38,6 \\
\hline 289526762 & 30 & 3428 & $\begin{array}{l}\text { Chain } \mathrm{D} \text {, enhancing the therapeutic properties of a protein by a desig } \\
\text { binding site }\end{array}$ & 100 \\
\hline 294979722 & 141 & 0 & Chain E, deoxy human normal adult hemoglobin & 56,7 \\
\hline 294979723 & 146 & 0 & Chain G, deoxy human normal adult hemoglobin & 89 \\
\hline 295321918 & 374 & 41579 & Chain J, model of alpha-actinin Chl bound to F-actin & 9,1 \\
\hline 119630802 & 740 & 78794 & Chromosome 20 open reading frame 75 & 2,7 \\
\hline 119568512 & 153 & 17486 & Chromosome 6 open reading frame 75 & 10,5 \\
\hline 10518503 & 444 & 49288 & Coagulation factor VII isoform B precursor & 3,4 \\
\hline 119581366 & 1261 & 135504 & Cordon-bleu homolog (mouse) & 2,3 \\
\hline 83582815 & 89 & 9881 & Cornifin-B & 19,1 \\
\hline 119602496 & 311 & 35475 & Cysteine/histidine-rich 1 & 4,2 \\
\hline 10719963 & 520 & 59956 & Cytochrome P450 4F8 & 3,1 \\
\hline 119581796 & 712 & 78265 & Cytoplasmic polyadenylation element binding protein 4 & 2,4 \\
\hline 119610301 & 2073 & 237519 & Dedicator of cytokinesis 11 & 0,9 \\
\hline
\end{tabular}


TABle 1: Continued.

\begin{tabular}{|c|c|c|c|c|}
\hline $\begin{array}{l}\text { Accession } \\
\text { number }\end{array}$ & $\begin{array}{c}\text { Number } \\
\text { of AAs }\end{array}$ & $\mathrm{MW}[\mathrm{Da}]$ & Description & $\Sigma$ Coverage \\
\hline 20141302 & 110 & 11277 & Dermcidin & 25,5 \\
\hline 55749932 & 470 & 53503 & Desmin & 10,9 \\
\hline 63054852 & 508 & 58371 & DNA nucleotidylexotransferase isoform 2 & 5,3 \\
\hline 119614620 & 977 & 109666 & Endoplasmic reticulum to nucleus signalling 1 & 1,6 \\
\hline 24418674 & 974 & 110429 & Exocyst complex component 4 & 1,5 \\
\hline 17369686 & 1087 & 123828 & Exportin-7 & 1,5 \\
\hline 22749363 & 434 & 49418 & F-box only protein 15 isoform 1 & 3,5 \\
\hline 119570461 & 1769 & 200655 & Fer-1-like 3, myoferlin (C. elegans) & 0,9 \\
\hline 119568019 & 1322 & 142839 & Fibronectin type III domain containing 1 & 1,5 \\
\hline 13129018 & 188 & 20994 & Gamma-glutamylcyclotransferase & 10,1 \\
\hline 119596338 & 147 & 16448 & Ganglioside-induced differentiation-associated protein 1-like 1 & 10,2 \\
\hline 46409304 & 443 & 48955 & Glutamate-rich protein 1 & 3,8 \\
\hline 119625129 & 215 & 24427 & Glycoprotein M6A & 7,4 \\
\hline 119621332 & 947 & 107158 & GREB1 protein & 1,5 \\
\hline 152031617 & 669 & 72408 & GTP-binding protein 1 & 2,1 \\
\hline 119625298 & 455 & 51153 & Guanylate cyclase 1 , soluble, alpha 3 & 2,9 \\
\hline 119583777 & 947 & 106793 & hCG1641824 & 2 \\
\hline 119584015 & 69 & 7604 & hCG1813122 & 17,4 \\
\hline 119597394 & 4919 & 535890 & hCG19253 & 0,4 \\
\hline 119582778 & 87 & 10173 & hCG1981126 & 12,6 \\
\hline 119610862 & 1925 & 215078 & hCG1986053 & 1,6 \\
\hline 119568453 & 491 & 54322 & hCG2030297 & 5,1 \\
\hline 119572490 & 576 & 62385 & hCG2040584 & 4,3 \\
\hline 119598528 & 57 & 6808 & hCG2045397 & 29,8 \\
\hline 4504517 & 205 & 22768 & Heat shock protein beta- 1 & 21 \\
\hline 119589211 & 147 & 16045 & Hemoglobin, delta & 62,6 \\
\hline 119589125 & 462 & 51643 & Hemopexin & 7,6 \\
\hline 121925 & 221 & 22336 & Histone H1.3 & 5,9 \\
\hline 5901922 & 378 & 44440 & Hsp90 cochaperone Cdc37 & 3,7 \\
\hline 164684901 & 94 & 11002 & Immunoglobulin heavy chain variable region & 18,1 \\
\hline 17366467 & 2758 & 313745 & Inositol 1,4,5-trisphosphate receptor type 1 & 0,6 \\
\hline 119623087 & 1257 & 133685 & Insulin receptor substrate 4 & 1 \\
\hline 226694184 & 1179 & 130077 & Integrin alpha-E & 1,7 \\
\hline 261878618 & 623 & 69452 & Inter-alpha-trypsin inhibitor heavy chain $\mathrm{H} 1$ isoform $\mathrm{C}$ & 2,3 \\
\hline 27477074 & 502 & 55848 & Interleukin-17 receptor B precursor & 2,6 \\
\hline 46397807 & 449 & 49715 & Keratin, type I cuticular Ha7 & 3,3 \\
\hline 195972866 & 584 & 58766 & Keratin, type I cytoskeletal 10 & 22,6 \\
\hline 239938886 & 623 & 62027 & Keratin, type I cytoskeletal 9 & 28,3 \\
\hline 238054406 & 644 & 65999 & Keratin, type II cytoskeletal 1 & 30,1 \\
\hline 239938650 & 639 & 65393 & Keratin, type II cytoskeletal 2 epidermal & 7,5 \\
\hline 143811411 & 590 & 62340 & Keratin, type II cytoskeletal 5 & 11,9 \\
\hline 5031839 & 564 & 60008 & Keratin, type II cytoskeletal 6A & 14,2 \\
\hline 238054404 & 564 & 60030 & Keratin, type II cytoskeletal 6B & 9 \\
\hline 59803089 & 564 & 59988 & Keratin, type II cytoskeletal 6C & 16,3 \\
\hline 90110027 & 483 & 53671 & Keratin, type II cytoskeletal 8 & 7,9 \\
\hline 119619543 & 916 & 102928 & KIAA1024 protein & 2,1 \\
\hline 119600758 & 1047 & 116840 & KIAA1128 & 4,3 \\
\hline
\end{tabular}


TABle 1: Continued.

\begin{tabular}{|c|c|c|c|c|}
\hline $\begin{array}{l}\text { Accession } \\
\text { number }\end{array}$ & $\begin{array}{l}\text { Number } \\
\text { of AAs }\end{array}$ & $\mathrm{MW}[\mathrm{Da}]$ & Description & $\Sigma$ Coverage \\
\hline 119583893 & 1420 & 158295 & Kinesin family member $13 \mathrm{~B}$ & 2,9 \\
\hline 231569458 & 629 & 70939 & Lactoperoxidase isoform 3 preproprotein & 2,5 \\
\hline 27436948 & 634 & 70618 & Lamin-A/C isoform 3 & 8,2 \\
\hline 119599090 & 222 & 25734 & Latexin & 5,4 \\
\hline 119628276 & 394 & 43749 & Mannosidase, alpha, class $1 \mathrm{C}$, member 1 & 6,4 \\
\hline 290457624 & 397 & 41734 & Mesoderm posterior protein 2 & 4,8 \\
\hline 115502451 & 496 & 53464 & Mothers against decapentaplegic homolog 6 & 4 \\
\hline 119573924 & 271 & 28644 & Myeloid cell leukemia sequence 1 (BCL2-related) & 7,4 \\
\hline 119610415 & 1737 & 199228 & Myosin, heavy polypeptide 8 , skeletal muscle, perinatal & 1,2 \\
\hline 33667040 & 1048 & 119352 & NACHT, LRR, and PYD domains-containing protein 8 & 2,7 \\
\hline 33624861 & 429 & 48129 & Nesprin-2 isoform 2 & 4 \\
\hline 93204871 & 628 & 70024 & Netrin-4 precursor & 2,4 \\
\hline 160332335 & 5890 & 628699 & Neuroblast differentiation-associated protein AHNAK & 4,5 \\
\hline 119625194 & 527 & 60213 & NIMA- (never in mitosis gene A-) related kinase 1 & 2,9 \\
\hline 156632525 & 714 & 80686 & Nuclear protein MDM1 & 2,4 \\
\hline 119570426 & 800 & 92490 & Nucleolar complex associated 3 homolog (S. cerevisiae) & 1,6 \\
\hline 74749412 & 510 & 57244 & Olfactomedin- 4 & 2,8 \\
\hline 24430183 & 638 & 73293 & Outer dense fiber protein 2 isoform 2 & 2,7 \\
\hline 21735584 & 820 & 93729 & Oxysterol-binding protein-related protein 3 isoform $\mathrm{D}$ & 1,7 \\
\hline 296439282 & 595 & 68541 & P2X purinoceptor 7 & 2,2 \\
\hline 237757297 & 643 & 70596 & Pannexin-2 isoform 2 & 2 \\
\hline 119626787 & 301 & 34291 & Phosphatidylinositol glycan, class $\mathrm{K}$ & 6,3 \\
\hline 74730959 & 315 & 35934 & PIH1 domain-containing protein 2 & 4,1 \\
\hline 74730663 & 189 & 20681 & Plasma cell-induced resident endoplasmic reticulum protein & 18,5 \\
\hline 296439496 & 1271 & 139580 & Pleckstrin homology domain-containing family $\mathrm{G}$ member 4B & 1,1 \\
\hline 119602579 & 2105 & 233975 & Plectin 1, intermediate filament binding protein $500 \mathrm{kDa}$ & 1 \\
\hline 150421625 & 764 & 83232 & Polymeric immunoglobulin receptor & 2,8 \\
\hline 123402 & 479 & 51177 & POU domain, class 2 , transcription factor 2 & 2,9 \\
\hline 22261792 & 1499 & 167582 & Probable phospholipid-transporting ATPase VA & 3,7 \\
\hline 32171249 & 190 & 21015 & Prostaglandin-H2 D-isomerase & 17,4 \\
\hline 119578886 & 247 & 26680 & Protease, serine, 3 (mesotrypsin) & 5,3 \\
\hline 122801 & 352 & 38974 & Protein AMBP; AltName: Full = Alpha-1 microglycoprotein & 6,5 \\
\hline 162416266 & 758 & 87316 & Protein dpy-19 homolog 2 & 1,7 \\
\hline 257743264 & 606 & 69420 & Protein THEMIS isoform 3 & 3,1 \\
\hline 296452931 & 1208 & 138572 & Protein timeless homolog & 1,3 \\
\hline 74733527 & 701 & 80649 & Pseudouridylate synthase 7 homolog-like protein & 2 \\
\hline 167016536 & 107 & 12037 & Putative nucleosome assembly protein 1-like 6 & 10,3 \\
\hline 74760358 & 247 & 26522 & Putative trypsin-6 & 12,2 \\
\hline 74712786 & 109 & 11855 & Putative uncharacterized protein FP588 & 18,4 \\
\hline 119631914 & 1896 & 211398 & RAP1 interacting factor homolog (yeast) & 0,8 \\
\hline 125987856 & 611 & 69368 & Rho-related BTB domain-containing protein 3 & 2,5 \\
\hline 119620511 & 39 & 4319 & Ribosomal protein $\mathrm{S} 27 \mathrm{a}$ & 41 \\
\hline 126215690 & 3280 & 373742 & RING finger protein 213 & 0,7 \\
\hline 296452978 & 1393 & 152659 & RNA polymerase II-associated protein 1 & 0,9 \\
\hline 119573716 & 93 & 10828 & S100 calcium binding protein A8 (calgranulin A) & 11,8 \\
\hline 119573719 & 114 & 13234 & S100 calcium binding protein A9 (calgranulin B) & 28,1 \\
\hline
\end{tabular}


TABle 1: Continued.

\begin{tabular}{|c|c|c|c|c|}
\hline $\begin{array}{l}\text { Accession } \\
\text { number }\end{array}$ & $\begin{array}{l}\text { Number } \\
\text { of AAs }\end{array}$ & MW [Da] & Description & $\Sigma$ Coverage \\
\hline 4506027 & 307 & 35057 & Serine/threonine-protein phosphatase 4 catalytic subunit & 4,9 \\
\hline 113576 & 609 & 69321 & Serum albumin precursor & 34,3 \\
\hline 119569088 & 107 & 12318 & SH3 domain binding glutamic acid-rich protein like 2 & 14 \\
\hline 119576122 & 262 & 29185 & Similar to CG12314 gene product & 7,3 \\
\hline 119620924 & 753 & 82996 & Similar to RIKEN cDNA 4632412 N22 gene & 2,5 \\
\hline 296452999 & 2785 & 318182 & Small subunit processome component 20 homolog & 0,9 \\
\hline 119589494 & 452 & 50195 & $\begin{array}{l}\text { Solute carrier family } 25 \text { (mitochondrial carrier; phosphate carrier), } \\
\text { member } 23\end{array}$ & 4,4 \\
\hline 119596056 & 314 & 33833 & Solute carrier family 9 (sodium/hydrogen exchanger), member 8 & 4,1 \\
\hline 119599799 & 450 & 51876 & Sorting nexin 4 & 4,2 \\
\hline 119628509 & 259 & 29439 & $\begin{array}{l}\text { Steroid-5-alpha-reductase, alpha polypeptide } 1 \text { (3-oxo-5 alpha-steroid } \\
\text { delta 4-dehydrogenase alpha 1) }\end{array}$ & 9,7 \\
\hline 119599133 & 506 & 58721 & TCDD-inducible poly(ADP-ribose) polymerase & 2,2 \\
\hline 109895218 & 526 & 57476 & Thymocyte selection-associated high mobility group box protein TOX & 6,1 \\
\hline 291045225 & 33423 & 3711285 & Titin isoform N2-A & 0,3 \\
\hline 119605952 & 641 & 71538 & TNF receptor-associated factor 7 & 2,7 \\
\hline 585328 & 80 & 8635 & Trefoil factor 3 & 22,5 \\
\hline 119573617 & 242 & 28050 & Tropomyosin 3 & 14,5 \\
\hline 14389309 & 449 & 49863 & Tubulin alpha-1C chain & 7,4 \\
\hline 47157315 & 1124 & 125019 & Tyrosine-protein kinase JAK3 & 1,3 \\
\hline 55977767 & 466 & 53619 & Vimentin & 19,7 \\
\hline 32483410 & 474 & 52883 & Vitamin D-binding protein precursor & 17,5 \\
\hline 119568661 & 331 & 36884 & WNT1 inducible signaling pathway protein 3 & 4,5 \\
\hline 20532312 & 653 & 74145 & Zinc finger protein 274 & 11,6 \\
\hline 149588643 & 679 & 77891 & Zinc finger protein 283 & 1,9 \\
\hline 140560957 & 590 & 68217 & Zinc finger protein $285 \mathrm{~A}$ & 2,4 \\
\hline 30580627 & 626 & 72145 & Zinc finger protein 441 & 2,2 \\
\hline 74759403 & 364 & 41163 & Zinc finger protein 589 & 4,7 \\
\hline 119603081 & 647 & 74123 & Zinc finger protein 595 & 2,5 \\
\hline 119598822 & 485 & 56018 & Zinc finger protein 639 & 2,5 \\
\hline 187671927 & 394 & 46069 & Zinc finger protein 763 & 3,8 \\
\hline 74758703 & 808 & 93088 & Zinc finger protein 841 & 2 \\
\hline
\end{tabular}

the only proteins with a $100 \%$ sequence similarity and the best scores from the search. ZNF441 (gi308153532, UniProt: Q8N8Z8) is a nuclear protein with 693 amino acids which belongs to the Krueppel $\mathrm{C}_{2} \mathrm{H}_{2}$-type zinc finger protein family, and it contains $19 \mathrm{C}_{2} \mathrm{H}_{2}$-type zinc fingers and $1 \mathrm{KRAB}-$ domain (UniProt entry).

ROC curve analysis showed that the optimal threshold for both ZNF441 and PLD6 was $\leq 1$ versus $>1$. Using these thresholds, all regression and persistence cases of the learning set were correctly classified. In the validation set, 9 of the 10 regression and all 10 persistence cases were correctly classified. Figure 4 illustrates the power of the two proteins to distinguish between regressive and persistent CIN2-3 lesions for all cases in both the learning and the test set.

\section{Discussion}

This study describes the results from analysis of three different datasets regarding regression or persistence of CIN23 lesions: one dataset from SELDI-TOF MS and two datasets from LC-MS/MS analysis. 


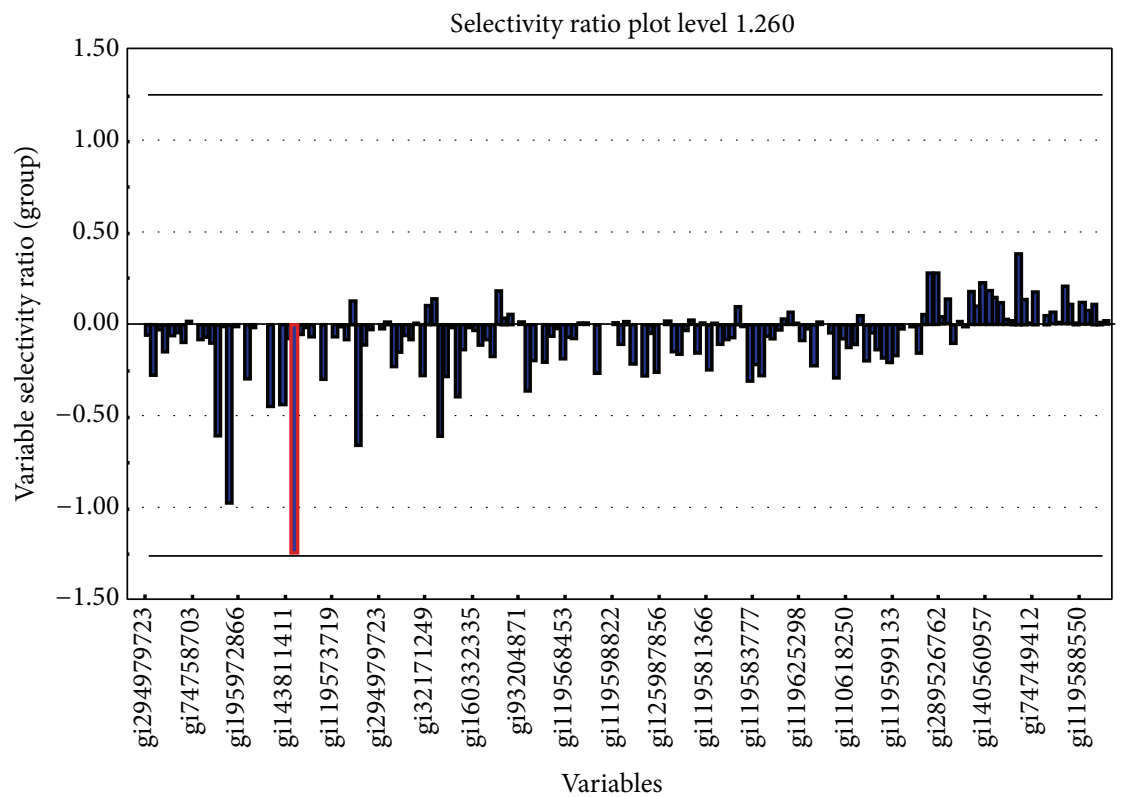

Figure 3: Selectivity ratio plot for all identified proteins. The selectivity ratio limit for a $90 \%$ mean corrected classification rate is shown as horizontal lines. The zinc finger protein 441 is marked with red square box.

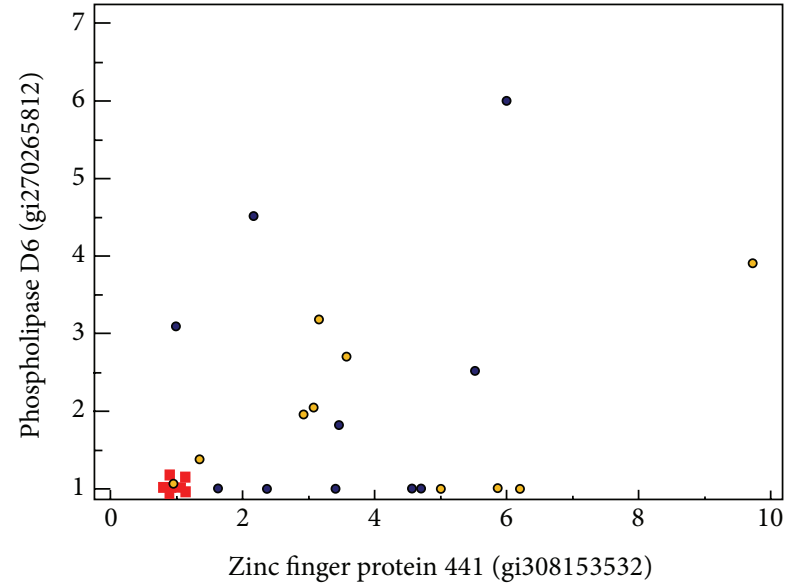

Persistence, both sets

○ Regression, learning set

- Regression, validation set

Figure 4: Scatter plot of the spectral count data for the zinc finger protein 441 and phospholipase D6 protein showing the discrimination between regression and persistence samples. The regression samples are shown further subdivided in learning (yellow circles) and validation (blue circles) sets.

For the SELDI-TOF MS study, supernatants from a total of 45 patient samples ( 5 CIN2-3 with regression and 40 CIN23 with persistence) were analysed. One discriminatory peak was found by developing a binary logistic regression model using the SELDI-TOF MS dataset, but no discrimination between CIN2-3 lesions with regression or persistence could be obtained. Other binding conditions for the CM10 chip could have been used, as well as other chip types, but this was not pursued further as obtaining protein identification from a SELDI-TOF MS peak proved challenging.

LC-MS/MS analysis was much more promising than SELDI-TOF. All three multivariate statistical methods applied on the normalized spectral count results gave the same result, indicating that ZNF441 can discriminate between regressive and persistent CIN2-3 lesions. To our knowledge the exact function of ZNF441 has not yet been revealed, but the large family of transcriptional regulators of KRAB-containing zinc finger proteins are known to act as tumour suppressors [26]. In general, zinc finger proteins are a highly abundant group of proteins that varies in both structure and function [27]. They are involved in several cellular activities, including development, differentiation, and tumour suppression [28]. A zinc finger is a peptide domain whose secondary structure is stabilized by a bound zinc ion and a zinc finger protein can contain between 1 and 40 such domains [27]. The C2H2domain is considered the "classical" zinc finger and is among the most abundent ones of the zink finger domains [28]. Zinc fingers were originally considered only as DNA-binding domains, but their role in protein-protein interactions has eventually been recognized [29]. Proteins with multiple zinc fingers can have two to three different types of binding activity through different fingers [28].

The Krueppel-associated box (KRAB-domain) is located near the N-terminal end of the protein, spans across 5075 amino acids, and is divided into two boxes ( $A$ and $B$ ). $\mathrm{KRAB}$-containing proteins are transcriptional repressors and use the zinc fingers to bind DNA [29]. KRAB-containing proteins are critical to cell differentiation, proliferation, apoptosis, and neoplastic transformation. Increased expression of the ZNF23 has been found to induce apoptosis in ovarian cancer cell lines [30]. ZNF431 functions as a transcriptional repressor for Patched1 (PTCH1) through binding to the 


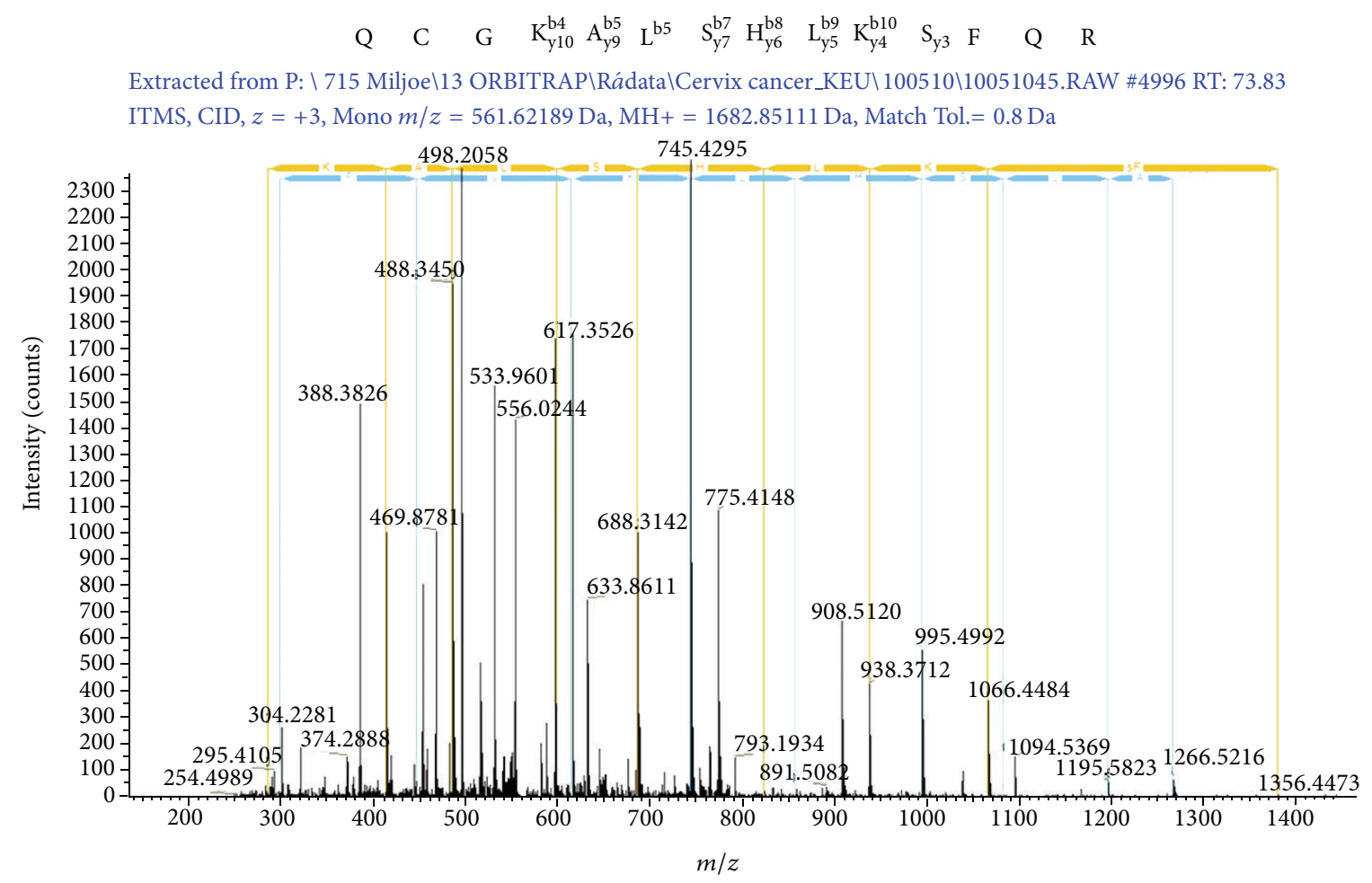

FIGURE 5: MS2 spectrum and amino acid sequence for the identified peptide from zinc finger protein 441 . The y-and b-series are also shown.

target promoter sequence [31]. PTCH1 is a member of the Hedgehog $(\mathrm{HH})$ family and acts as a negative regulator of the $\mathrm{HH}$ pathway. This pathway is important during embryonic development but has also been shown to be active during cancer development in adults. [32]. Repression of PTCH1 in a gastric cell line [33] was shown to correlate with high level of methylation of $\mathrm{CpG}$ islands at regulatory sequences and this could be associated with the development of gastric cancer. Another zinc finger protein, ZNF411, was found to suppress the MAP kinase signalling pathway [34], which is important for cell cycle checkpoints [35]. Overexpression of this pathway has been reported in different squamous cell carcinomas [36, 37]. The relationship between CIN grade and the MAP kinase pathway has also been investigated and was found to be an early marker for cervical carcinogenesis but not related to virus clearance [38]. Furthermore, the oncogenic E6 and E7, expressed in high risk HPV and known to play an important role in CIN tumour progression, also contain zinc finger domains, as recently reviewed by Ruttkay-Nedecky et al. [39]. In fact, new cell-permeable artificial zinc finger proteins (AZPs) have been launched as potential antiviral drug candidates that are able to reduce HPV replication [40, 41].

Phospholipase D6 (PLD6) was only reported by the CART analysis as contributing to the discrimination. In general, phospholipase D (PLD) proteins have been implicated in membrane trafficking [42, 43], cytoskeletal reorganization [44], endocytosis, exocytosis, cell migration, and cell proliferation [45]. The mouse homologue Zucchini ( $m Z u c)$, also known as PLD6, has been shown to possess single strand-specific nuclease activity. This endoribonuclease has been shown to be essential for primary piRNA biogenesis $[46,47]$. piRNAs are a distinct class of small RNAs, called Piwi-interacting RNAs, and have been discovered in both mammalian [48] and Drosophila germline [49]. They cluster at transposon loci in male germline stem cells and it has been suggested that piRNAs and their associated Piwi proteins are involved in epigenetic mechanisms like methylation and chromatin modifications [49]. A piRNA population has also been identified in the He-La cervical cancer cell line [50]. In germline stem cells these components are critical for silencing mobile genetic elements via DNA methylation. [51]. Furthermore, piRNAs have been detected in human cancer and somatic cells, and epigenetic disruption of the PIWI/piRNA pathway is indeed a hallmark for cancer development in testis [52]. Diminished piRNA expression has been found in testicular tumours as compared to normal testis.

In the current study, PLD6 was found to be expressed in most regression cases $(12 / 20)$ but not in the persistent cases. The exact mechanisms for the epigenetic silencing exerted by the piRNA-PIWI pathway components remain unsolved and identification of additional protein components is crucial for a better understanding of the role of piRNAs in cancer [53].

This study and a previous study [17] show that CIN biopsies shed a complex mixture of proteins into a cell culture medium when placed at $4^{\circ} \mathrm{C}$ for 24 hours. For the LC-MS/MS study, supernatants from two series of 20 patient samples each (10 CIN2-3 with regression and 10 with persistence in each series) were analysed using a bottom-up shotgun proteomics approach [54] in which the proteins were digested 
into smaller peptides using trypsin. The peptide mixture was then analysed using unidimensional LC-MS/MS. Samples were pretreated by an immunoaffinity adsorbent which was previously validated by SDS-PAGE and LC-MS/MS (Supplementary Figure 1). Despite the depletion of seven high abundance proteins including immunoglobulins and albumin, peptides from these proteins were detected, while transferrin was not found at all after depletion. In addition, not unexpectedly, hemoglobins constitute a relatively large part of the identified proteins (cervical tissues with CIN23 are usually richly vascularised) and should be included in future depletion work. The complexity of the depleted fraction is still a challenge. Further fractionation of the depleted samples prior to the LC-MS/MS analysis would be an advantage to increase the supernatant proteome coverage and also possibly the sequence coverage of the identified proteins. This fractionation could be obtained using $2 \mathrm{D}$ gel separation of the protein mixture or, for example, a cation exchange fractionation of the peptides after digestion. Another option is enrichment of subproteomes like phosphorylated proteins or glycosylated proteins. The results in this study should of course be validated by analysing a larger number of samples and also by analyses using other methodology like immunohistochemistry.

\section{Conclusions}

Using three different statistical methods to analyse normalized spectral count data, this study has identified zinc finger protein 441 as a highly discriminating factor between CIN2-3 regressive and persistent lesions. Phospholipase D6 contributes to the discrimination.

Interestingly the two proposed proteins are important factors for repression of tumour growth. Zinc finger proteins constitute the largest family of transcriptional regulators in mammals with important DNA binding domains and are also involved in protein-protein interactions. Their ability to induce apoptosis has been shown, as well as their function as nuclear transcriptional repressors of genes involved in signal transduction important for development of carcinogenesis. PLD6 is involved in biogenesis of piRNAs, small noncoding RNAs involved in hypermethylation events and important for transcriptional, epigenetic, and signalling pathways alterations. In line with these findings, both PLD6 and ZNF441 were almost absent in the persistent CIN2-3 cases contrary to the regression cases (Figure 4).

The depletion of seven high abundance proteins followed by a unidimensional separation of tryptic digests of nondepleted protein mixtures shows the potential of the described method for collection of proteins from CIN biopsies. From a prognostic aspect, the findings are promising tools for further investigation and understanding of the biology behind regression of precancerous cervical lesions.

\section{Conflict of Interests}

The authors declare that they have no conflict of interests regarding the publication of this paper.

\section{Acknowledgments}

Thanks are due to Pattern Recognition Systems (Bergen, Norway) and Professor Olav Kvalheim at the University of Bergen (Bergen, Norway) for making Sirius version 8.1 available for this work. Thanks are also due to Akvamiljø AS for providing access to both the SELDI-TOF MS and the LTQOrbitrap. Funding for this research was provided by the Folke Hermansen Foundation in 2007 and Helse Vest in 2011.

\section{References}

[1] A. Jemal, F. Bray, M. M. Center, J. Ferlay, E. Ward, and D. Forman, "Global cancer statistics," CA: A Cancer Journal for Clinicians, vol. 61, no. 2, pp. 69-90, 2011.

[2] H. zur Hausen, "Papillomaviruses in the causation of human cancers-a brief historical account," Virology, vol. 384, no. 2, pp. 260-265, 2009.

[3] R. P. Insinga, E. J. Dasbach, and E. H. Elbasha, "Epidemiologic natural history and clinical management of human papillomavirus (HPV) Disease: a critical and systematic review of the literature in the development of an HPV dynamic transmission model," BMC Infectious Diseases, vol. 9, article 119, 2009.

[4] J. P. Baak, A. J. Kruse, S. J. Robboy, E. A. Janssen, B. van Diermen, and I. Skaland, "Dynamic behavioural interpretation of cervical intraepithelial neoplasia with molecular biomarkers," Journal of Clinical Pathology, vol. 59, no. 10, pp. 1017-1028, 2006.

[5] A. C. Munk, A. J. Kruse, B. van Diermen et al., "Cervical intraepithelial neoplasia grade 3 lesions can regress," APMIS, vol. 115, no. 12, pp. 1409-1414, 2007.

[6] M. R. McCredie, C. Paul, K. J. Sharples et al., "Consequences in women of participating in a study of the natural history of cervical intraepithelial neoplasia 3," Australian and New Zealand Journal of Obstetrics and Gynaecology, vol. 50, no. 4, pp. 363-370, 2010.

[7] A. G. Ostor, "Natural history of cervical intraepithelial neoplasia- a critical review," International Journal of Gynecological Pathology, vol. 12, no. 2, pp. 186-192, 1993.

[8] P. P. Martin-Hirsch, E. Paraskevaidis, A. Bryant, H. O. Dickinson, and S. L. Keep, "Surgery for cervical intraepithelial neoplasia," Cochrane Database of Systematic Reviews, vol. 16, no. 6, Article ID CD001318, 2010.

[9] M. Kyrgiou, G. Koliopoulos, P. Martin-Hirsch, M. Arbyn, W. Prendiville, and E. Paraskevaidis, "Obstetric outcomes after conservative treatment for intraepithelial or early invasive cervical lesions: systematic review and meta-analysis," The Lancet, vol. 367, no. 9509, pp. 489-498, 2006.

[10] L. Sadler, A. Saftlas, W. Wang, M. Exeter, J. Whittaker, and L. McCowan, "Treatment for cervical intraepithelial neoplasia and risk of preterm delivery," The Journal of the American Medical Association, vol. 291, no. 17, pp. 2100-2106, 2004.

[11] A. S. Kadish, P. Timmins, Y. Wang et al., "Regression of cervical intraepithelial neoplasia and loss of human papillomavirus (HPV) infection is associated with cell-mediated immune responses to an HPV type 16 E7 peptide," Cancer Epidemiology Biomarkers and Prevention, vol. 11, no. 5, pp. 483-488, 2002.

[12] A. C. Munk, E. Gudlaugsson, I. T. Ovestad et al., "Interaction of epithelial biomarkers, local immune response and condom use in cervical intraepithelial neoplasia 2-3 regression," Gynecologic Oncology, vol. 127, no. 3, pp. 489-494, 2012. 
[13] I. T. Ovestad, E. Gudlaugsson, I. Skaland et al., "The impact of epithelial biomarkers, local immune response and human papillomavirus genotype in the regression of cervical intraepithelial neoplasia grades 2-3," Journal of Clinical Pathology, vol. 64, no. 4, pp. 303-307, 2011.

[14] I. T. Ovestad, E. Gudlaugsson, I. Skaland et al., "Local immune response in the microenvironment of CIN2-3 with and without spontaneous regression," Modern Pathology, vol. 23, no. 9, pp. 1231-1240, 2010.

[15] A. J. Kruse, I. Skaland, E. A. Janssen et al., "Quantitative molecular parameters to identify low-risk and high-risk early CIN lesions: role of markers of proliferative activity and differentiation and $\mathrm{Rb}$ availability," International Journal of Gynecological Pathology, vol. 23, no. 2, pp. 100-109, 2004.

[16] J. P. Baak and A. J. Kruse, "Use of biomarkers in the evaluation of CIN grade and progression of early CIN," Methods in Molecular Medicine, vol. 119, pp. 85-99, 2005.

[17] K. E. Uleberg, A. C. Munk, C. Brede et al., "Identification of water soluble proteins recovered from biopsies with high-grade intraepithelial neoplasia," Journal of Proteomics, vol. 9, no. 36, 2011.

[18] K. E. Uleberg, A. C. Munk, C. Brede et al., "Discrimination of grade 2 and 3 cervical intraepithelial neoplasia by means of analysis of water soluble proteins recovered from cervical biopsies," Proteome Science, vol. 9, article 36, 2011.

[19] E. I. Chen and J. R. Yates III, "Cancer proteomics by quantitative shotgun proteomics," Molecular Oncology, vol. 1, no. 2, pp. 144159, 2007.

[20] Quality assurance manual, Norwegian Cancer Registry, National advisory board for the Norwegian cervical cancer screening program, 2012, http://www.kreftregisteret.no/no/ Forebyggende/Masseundersokelsen-mot-livmorhalskreft.

[21] K. E. Uleberg, A. C. Munk, I. Skaland et al., "A protein profile study to discriminate CIN lesions from normal cervical epithelium," Cellular Oncology, vol. 34, no. 5, pp. 443-450, 2011.

[22] G. Zegels, G. A. van Raemdonck, E. P. Coen, W. A. Tjalma, and X. W. M. van Ostade, "Comprehensive proteomic analysis of human cervical-vaginal fluid using colposcopy samples," Proteome Science, vol. 7, article 17, 2009.

[23] T. Rajalahti, A. C. Kroksveen, R. Arneberg et al., "A multivariate approach to reveal biomarker signatures for disease classification: application to mass spectral profiles of cerebrospinal fluid from patients with multiple sclerosis," Journal of Proteome Research, vol. 9, no. 7, pp. 3608-3620, 2010.

[24] T. Rajalahti, R. Arneberg, A. C. Kroksveen, M. Berle, K. Myhr, and O. M. Kvalheim, "Discriminating variable test and selectivity ratio plot: quantitative tools for interpretation and variable (biomarker) selection in complex spectral or chromatographic profiles," Analytical Chemistry, vol. 81, no. 7, pp. 2581-2590, 2009.

[25] T. Rajalahti, R. Arneberg, F. S. Berven, K. M. Myhr, R. J. Ulvik, and O. M. Kvalheim, "Biomarker discovery in mass spectral profiles by means of selectivity ratio plot," Chemometrics and Intelligent Laboratory Systems, vol. 95, no. 1, pp. 35-48, 2009.

[26] R. Urrutia, "KRAB-containing zinc-finger repressor proteins," Genome Biology, vol. 4, no. 10, article 231, 2003.

[27] J. H. Laity, B. M. Lee, and P. E. Wright, "Zinc finger proteins: new insights into structural and functional diversity," Current Opinion in Structural Biology, vol. 11, no. 1, pp. 39-46, 2001.

[28] S. Iuchi, "Three classes of $\mathrm{C}_{2} \mathrm{H}_{2}$ zinc finger proteins," Cellular and Molecular Life Sciences, vol. 58, no. 4, pp. 625-635, 2001.
[29] K. J. Brayer and D. J. Segal, "Keep your fingers off my DNA: protein-protein interactions mediated by $\mathrm{C}_{2} \mathrm{H}_{2}$ zinc finger domains," Cell Biochemistry and Biophysics, vol. 50, no. 3, pp. 111-131, 2008.

[30] C. Huang, S. Yang, R. Ge, H. Sun, F. Shen, and Y. Wang, "ZNF23 induces apoptosis in human ovarian cancer cells," Cancer Letters, vol. 266, no. 2, pp. 135-143, 2008.

[31] Z. He, J. Cai, J. W. Lim, K. Kroll, and L. Ma, "A novel KRAB domain-containing zinc finger transcription factor ZNF431 directly represses Patched1 transcription," The Journal of Biological Chemistry, vol. 286, no. 9, pp. 7279-7289, 2011.

[32] J. L. Merchant, M. Saqui-Salces, and M. El-Zaatari, "Hedgehog signaling in gastric physiology and cancer," Progress in Molecular Biology and Translational Science, vol. 96, pp. 133-156, 2010.

[33] Y. Zuo and Y. Song, "Detection and analysis of the methylation status of PTCH1 gene involved in the hedgehog signaling pathway in a human gastric cancer cell line," Experimental and Therapeutic Medicine, vol. 6, no. 6, pp. 1365-1368, 2013.

[34] H. Liu, C. Zhu, J. Luo et al., "ZNF411, a novel KRAB-containing zinc-finger protein, suppresses MAP kinase signaling pathway," Biochemical and Biophysical Research Communications, vol. 320, no. 1, pp. 45-53, 2004.

[35] A. Poehlmann and A. Roessner, "Importance of DNA damage checkpoints in the pathogenesis of human cancers," Pathology Research and Practice, vol. 206, no. 9, pp. 591-601, 2010.

[36] J. L. Lessard, R. A. Robinson, and H. T. Hoffman, "Differential expression of ras signal transduction mediators in verrucous and squamous cell carcinomas of the upper aerodigestive tract," Archives of Pathology and Laboratory Medicine, vol. 125, no. 9, pp. 1200-1203, 2001.

[37] K. Mishima, E. Yamada, K. Masui et al., "Overexpression of the ERK/MAP kinases in oral squamous cell carcinoma," Modern Pathology, vol. 11, no. 9, pp. 886-891, 1998.

[38] M. Branca, M. Ciotti, D. Santini et al., "Activation of the ERK/MAP kinase pathway in cervical intraepithelial neoplasia is related to grade of the lesion but not to high-risk human papillomavirus, virus clearance, or prognosis in cervical cancer," American Journal of Clinical Pathology, vol. 122, no. 6, pp. 902911, 2004.

[39] B. Ruttkay-Nedecky, A. M. Jimenez Jimenez, L. Nejdl et al., "Relevance of infection with human papillomavirus: the role of the p53 tumor suppressor protein and E6/E7 zinc finger proteins (Review)," International Journal of Oncology, vol. 43, no. 6, pp. 1754-1762, 2013.

[40] T. Mino, T. Mori, Y. Aoyama, and T. Sera, "Gene- and proteindelivered zinc finger-staphylococcal nuclease hybrid for inhibition of DNA replication of human papillomavirus," PLoS ONE, vol. 8, no. 2, Article ID e56633, 2013.

[41] T. Mino, T. Mori, Y. Aoyama, and T. Sera, "Inhibition of human papillomavirus replication by using artificial zinc-finger nucleases," Nucleic Acids Symposium Series, no. 52, pp. 185-186, 2008.

[42] J. G. Donaldson, "Phospholipase D in endocytosis and endosomal recycling pathways," Biochimica et Biophysica ActaMolecular and Cell Biology of Lipids, vol. 1791, no. 9, pp. 845-849, 2009.

[43] M. G. Roth, "Molecular mechanisms of PLD function in membrane traffic," Traffic, vol. 9, no. 8, pp. 1233-1239, 2008.

[44] M. McDermott, M. J. Wakelam, and A. J. Morris, "Phospholipase D," Biochemistry and Cell Biology, vol. 82, no. 1, pp. 225253, 2004. 
[45] D. A. Foster and L. Xu, "Phospholipase D in cell proliferation and cancer," Molecular Cancer Research, vol. 1, no. 11, pp. 789800, 2003.

[46] J. J. Ipsaro, A. D. Haase, S. R. Knott, L. Joshua-Tor, and G. J. Hannon, "The structural biochemistry of Zucchini implicates it as a nuclease in piRNA biogenesis," Nature, vol. 491, no. 7423, pp. 279-283, 2012.

[47] H. Nishimasu, H. Ishizu, K. Saito et al., "Structure and function of Zucchini endoribonuclease in piRNA biogenesis," Nature, vol. 491, no. 7423, pp. 284-287, 2012.

[48] T. Esposito, S. Magliocca, D. Formicola, and F. Gianfrancesco, "PiR_015520 belongs to Piwi-associated RNAs regulates expression of the human melatonin receptor 1A gene," PLoS ONE, vol. 6, no. 7, Article ID e22727, 2011.

[49] H. Lin and H. Yin, "A novel epigenetic mechanism in Drosophila somatic cells mediated by PIWI and piRNAs," Cold Spring Harbor Symposia on Quantitative Biology, vol. 73, pp. 273-281, 2008.

[50] Y. Lu, C. Li, K. Zhang et al., "Identification of piRNAs in Hela cells by massive parallel sequencing," BMB Reports, vol. 43, no. 9, pp. 635-641, 2010.

[51] V. N. Kim, "Small RNAs just got bigger: piwi-interacting RNAs (piRNAs) in mammalian testes," Genes and Development, vol. 20, no. 15, pp. 1993-1997, 2006.

[52] H. J. Ferreira, H. Heyn, X. Garcia del Muro et al., "Epigenetic loss of the PIWI/piRNA machinery in human testicular tumorigenesis," Epigenetics, vol. 9, no. 1, pp. 113-118, 2013.

[53] S. Siddiqi, M. Terry, and I. Matushansky, "Hiwi mediated tumorigenesis is associated with DNA hypermethylation," PloS ONE, vol. 7, no. 3, Article ID e33711, 2012.

[54] S. K. Swanson and M. P. Washburn, "The continuing evolution of shotgun proteomics," Drug Discovery Today, vol. 10, no. 10, pp. 719-725, 2005. 

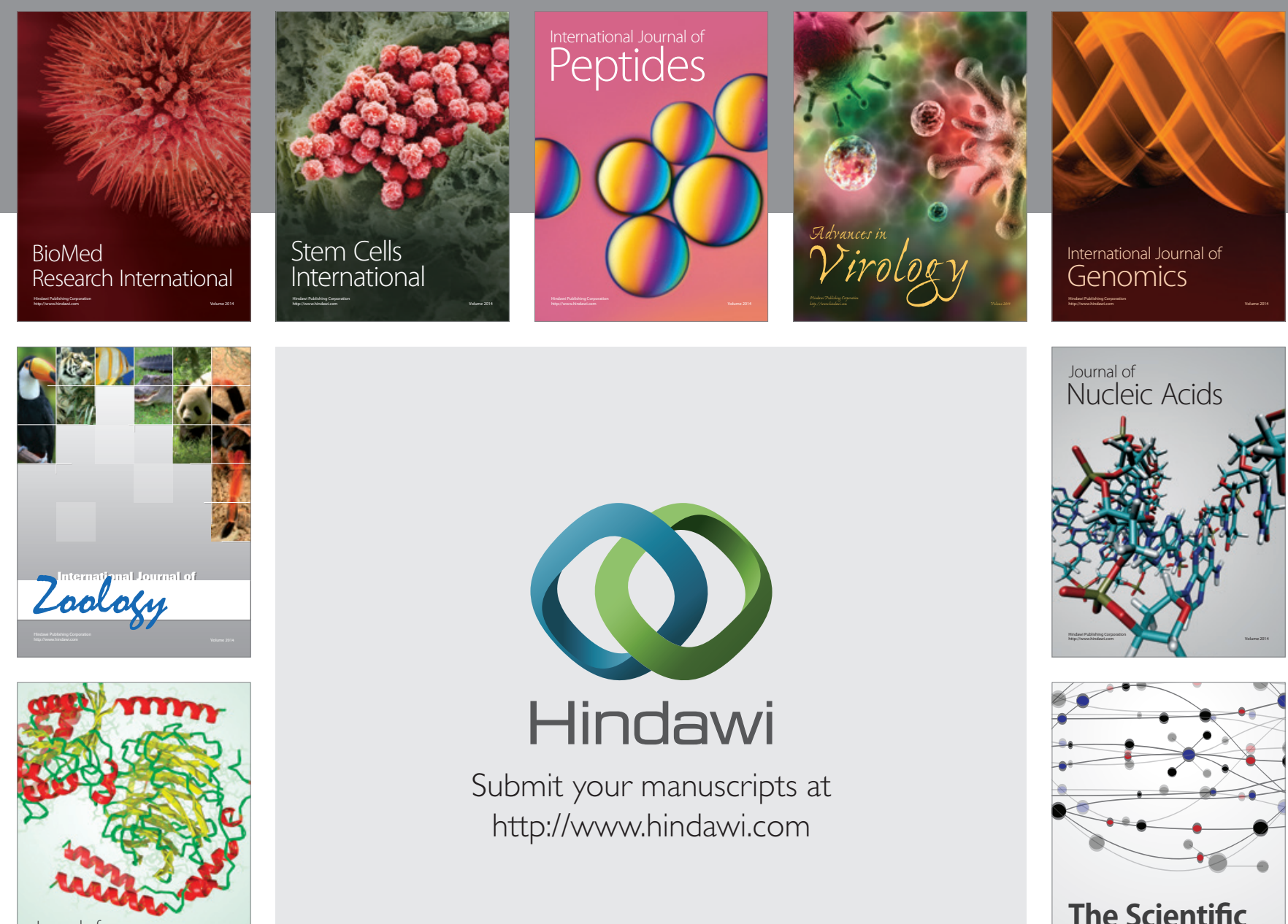

Submit your manuscripts at

http://www.hindawi.com

Journal of
Signal Transduction
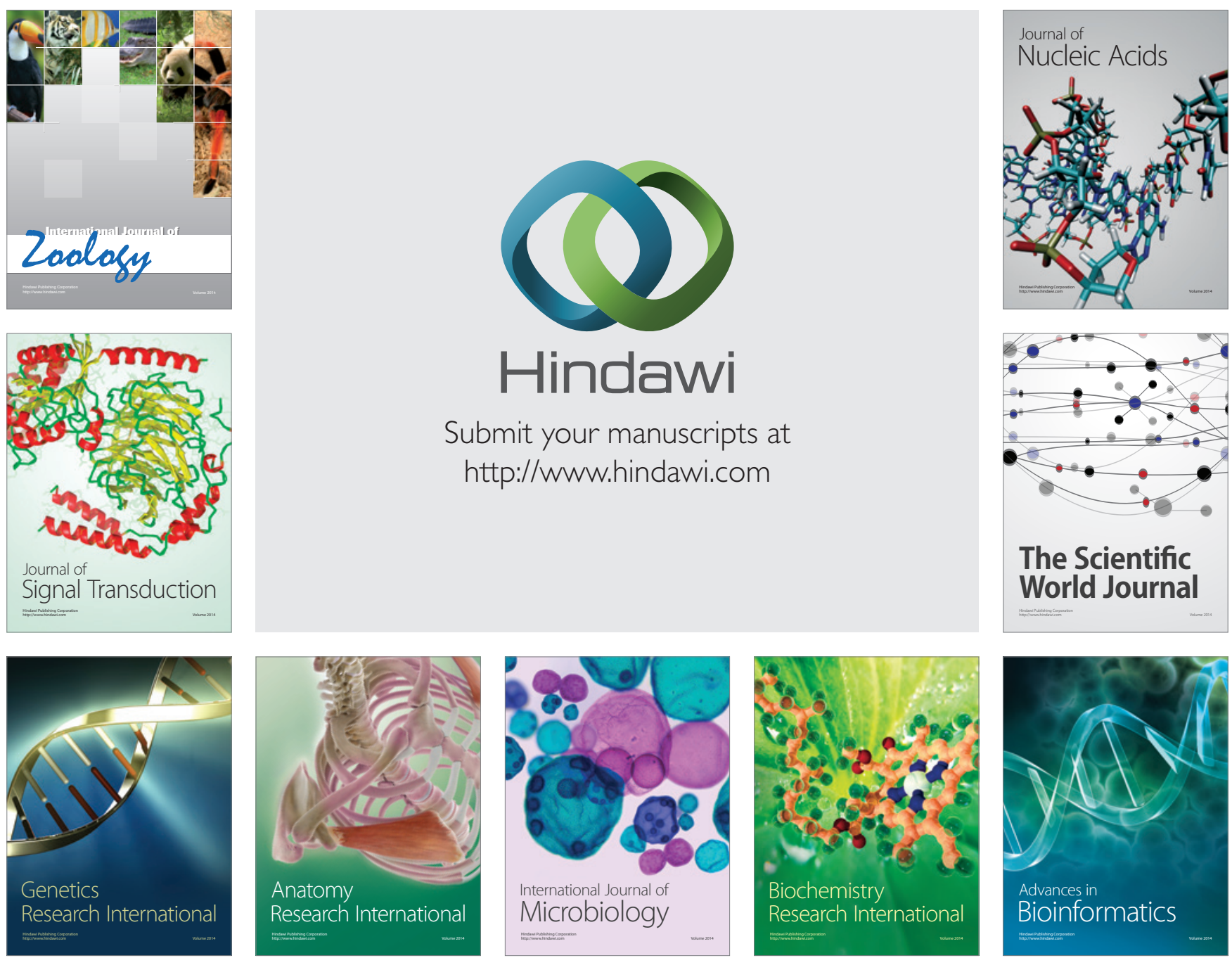

The Scientific World Journal
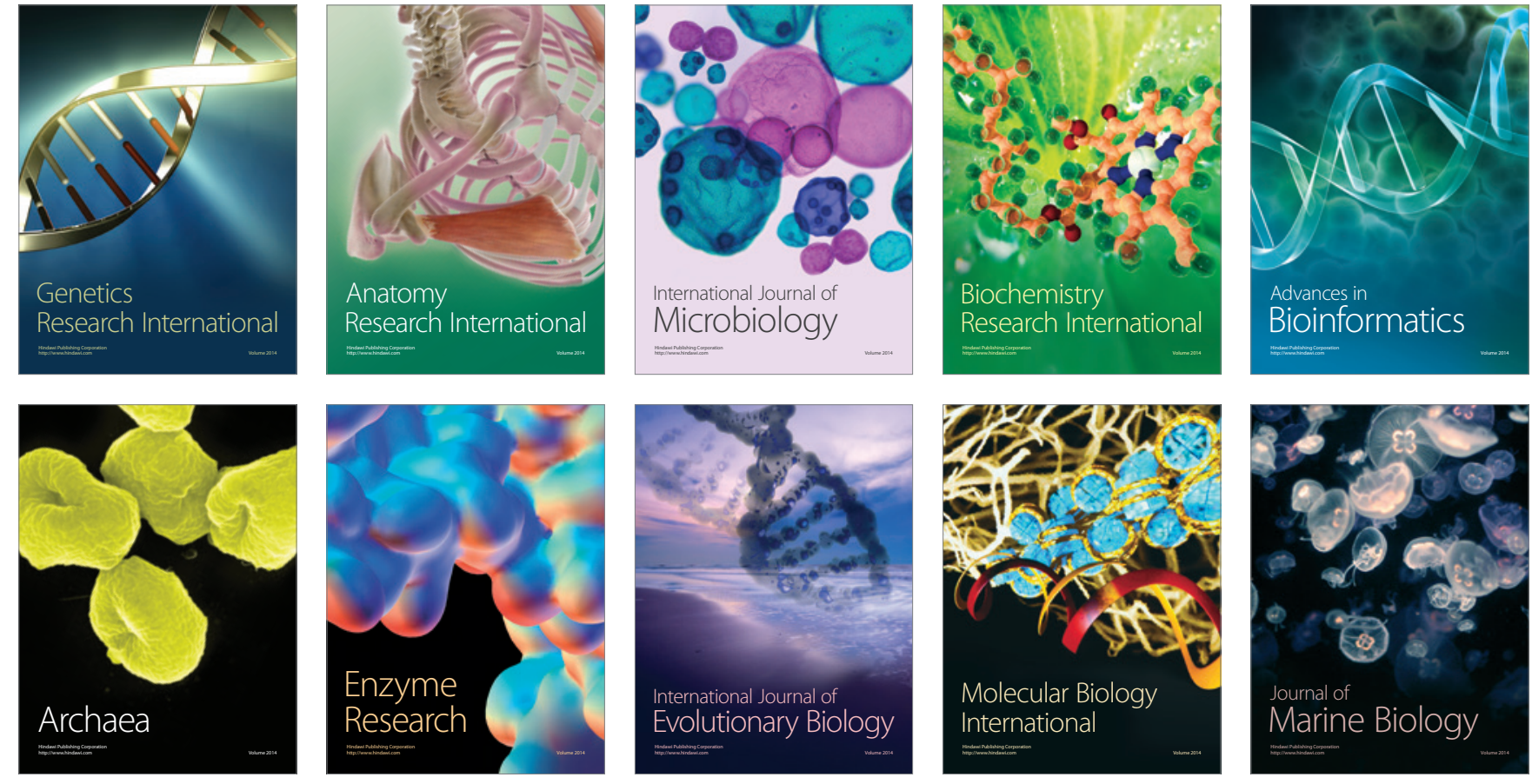